\title{
Finding Knowledge from Indonesian Traditional Medicine using Semantic Web Rule Language
}

\author{
Ridowati Gunawan $^{1}$, Khabib Mustofa ${ }^{2}$ \\ ${ }^{1,2}$ Departement of Computer Science and Electronics, Universitas Gadjah Mada, Yogyakarta, Indonesia \\ ${ }^{1}$ Departement of Informatics, Sanata Dharma University, Yogyakarta, Indonesia
}

\begin{tabular}{l} 
Article Info \\
\hline Article history: \\
Received Oct 27, 2016 \\
Revised Jul 15, 2017 \\
Accepted Aug 5, 2017 \\
\hline Keyword: \\
Ontology \\
Semantic Web Rule Language \\
Jamu
\end{tabular}

\begin{abstract}
One of the natural resources in Indonesia is a lot of plants which can be used in healing diseases. Thosekinds of plants can be used in "Jamu". Jamu is a name given to traditional medicine in Indonesia. Usually Jamu is composed from several plants as ingredients. Particularly, some parts of the plant like the leaves, roots, or branches have different purpose in Jamu. Nowadays the knowledge about Jamu can be known by building Ontology. Ontology can be built and developed to enrich the content. Knowledge in Ontology is built by several rules using Semantic Web Rule Language (SWRL).Knowledge gained from SWRL is easily searchable so that users can double check the results obtained.
\end{abstract}

\section{Corresponding Author:}

Ridowati Gunawan,

Department of Informatics,

Sanata Dharma University, Yogyakarta, 55282, Indonesia.

Email: ridowati.gunawan@ugm.ac.id,rido@usd.ac.id

\section{INTRODUCTION}

Jamu as an Indonesian traditional medicine has been widely used by most people in Indonesia [1]. Jamuis composed from several herbs that have been believed can heal diseases. The use of Jamu as a medicine has been proven since a long time ago. Relief "Karmawibhangga" found in Borobudur temple can be used as a proof of the tradition of drinking Jamu. The word Jamu in Javanese, "Jampi", has been found in ancient script like "Ghatotkacasraya" (Mpu Panuluh). Also it has been found in "Serat Centini 1814", "Serat Kawruh Chapter Jampi-jampi Jawi 1831".

In Indonesia, Jamu can be made by anybody including home industry or large manufacture. As a home industry, normally it is made based on the need of the society. Ingredients of certain Jamuare passed on from generation to generation. As an industry, on the contrary, ingredients made by a Jamu manufacturer are registered to Indonesian food and drug authority "BPOM". As a heritance, property of Jamu has to be maintained and knowledge about Jamu has to be developed. In 2010, Indonesian Government, through ministry of health, made a regulation about Jamu'sscientification[2]. This means Jamu produced from herbs in Indonesia has to have some measured purpose.Because many herbs can be used as Jamu and so many Jamusare found in society, science analysis between Jamu formula and the herbs used to compose it is needed. Jamuis composed from several plants which can be used to cure some diseases. One plant can be usedfor several kinds of Jamu. Every plants has special efficacy. One same kind of Jamu produced by different manufacturers can be composed by different kind of plants. This can be ambiguous for somebody who will consume that Jamu. A product guideline of which Jamu to be consumed can resolve this situation.

Herbs in Indonesia have different characteristics and different purposes. Some parts of the plants used to make Jamu will have different property. Environment from which those plants are taken will affect the use of them. Potion of every plant will compose different kind of Jamu with certain property. Sufficient 
knowledge about composition and the use of herbs inJamuis needed to use Jamu as a medicine so mutual harm from each plant can be avoided. With such knowledge, finding new herbs composition to compose Jamu to cure diseases is probable. Knowledge of Jamu, plants and parts of the plants used, has to be maintained and spread through society so the society can gain benefit from that inherited Indonesian knowledge. One of the technologies used to develop knowledge about Jamu is by using semantic web. Semantic web offering Ontology as a form of base knowledge can describe a relation between Jamu manufactured by a company, plants that they use parts of the plants, composition, and property of every Jamu and property of plants used.

Ontology is used to communicate between user and computer and furthermore it can give knowledge to the user. From ontology, new rules can be developed to make user easier to gain the previously unknown knowledge. Building ontology about Jamu and building the rules by using SWRL will allow users to get infomation of Jamu. Ontology built can be developed continously to produce a complete ontology about Jamu. Combination of the use of SWRL will ease the testing of the knowledge truth acquired. Science analysis about Jamu to gain correlation between plants, Jamuand property about Jamu uses statistical models [3]. Method used in this case is Biplot, Partial Least Square Discriminant Analysis (PLS-DA) and Bootstrapping. The method developed is to classify the efficacy of the Jamu formula. The Analysis is conducted on 3138 types of Jamu by dividing them into 9 groups of Jamu's effect. Accuracy test by using 5 fold produced $71.6 \%$ accuracy rate. The relation between the effects and formula of Jamu can be illustrated in different models, namely by building relation model with Ontology. Although Ontology development can not show the level of accuracy, it can ease users in understanding the relationship between Jamu formula and their benefits. Classification that already has high accuracy can be used as a model in the development of Ontology.

SH Wijaya [4] is developing network based study to predict correlation between plants and diseases. Jamu network is built based on similarity of ingredients used and then Jamu is clustered by using clustering network algorithm named DPClusO. This relation of plants-disease is then predicted by seeking the dominant disease and plants related to chosen Jamu cluster.From the experiment conducted, $90 \%$ of the prediction result generate correct information. The downside of this method occurs on the large data, the relation betwen Jamu formula and the disease become low, although the prediction can still be done. Yang [5] conducted research about one of Oriental Herbs, especially traditional Korean medicine from Bangyakhappyeon. His research shows a relation between symptoms and herbs material using association rule technique. Support value, confidence and lift are used to build its association rule. Minimum confidence level used by this research is $20 \%$. Confidence value and lift are used to justify the strength of rule composed. Radar Chart and NetMiner are used to build network analysis from formed association rule. The utilization of medicinal plants has been done in various ways, especially by using classification and association techniques. The correlation between medicinal plants and the benefits can be shown, but the collaboration of the use of knowledge about medicinal plants can not be done yet because the focus is only on a single knowledge base.

Semantic Web is an extension of the existing site, where the semantic web has content which is understood by humans and machines. There should be a common understanding between machines and humans against an object. For example, a word Apple should have the same concept between machines and humans. Is an apple a Fruit or apple as a Brand concept? To give meaning to the concept and eliminating another sense of the concept, it is necessary to add metadata to each concept discussed. Due to the addition of this metadata, intelligent machines will be produced because they do not give false information about a particular concept and the information search engines will become more rapid.

Integration between semantic web and SWRL (Semantic Web Rule Language) is to support interoperability rule-based system [6].Technically how the rule-making process ranging from the development of Ontology, SWRL and utilization JESS is generally described in the paper. The system can also be made based on Ontology and SWRL to help choosing a drug used as an anti-diabetes drug [7]. Statistics from the International Diabetes Federation (IDF) showed over 246 million people are affected by diabetes worldwide. Two main knowledgesare used to build Ontology, the data about the drugs used to treat diabetes patients and information about the patients. Experiment was done by building 6 rules by using SWRL and JESS contained in the software Protege. Results of the rules are entered into the recommendation system test the precision accuracy by using the data of 20 patients who produced $100 \%$ test results. Accuracy test is still very minimal, recommendation systems still need to be confirmed with more amount of data.

In particular, Ontology of Indonesia ethnomedicine has been developed in the field of the use of medicinal plants. Trials are conducted using twenty questions that are built with SPARQL [8]. In addition to plants and its property, the class built involves ethnic elements where the plant is obtained, because geographically Indonesia has many islands and not all the places in Indonesia has the same medicinal plant species. However, the class built just focus on one herb and the efficacy it has, and does not incorporate the combined efficacy and composition of herbs that can be used to make Jamu. The integration of data and 
processes queries using SWRL for Ontology has been built based on natural materials, chemicals and diseases. Ontology and SWRL can give rules concerning natural food ingredients to treat the diseases caused by organism [9]

Ontology using OWL and SWRL isalso developed for Indian medicinal plants, named MPONTOLOGY. Technically, ontology is built using Protege 3.4.4, queries using SQWRL, checking data inconsistencies using Pellet and rules built with SWRL. The property of the plant itself is the color, flavor, and size [10]. E-Health systems can also be made by Ontology. Users will include symptoms suffered and the system will give the approriate plant recommendations. By using Ontology they make rules that can be entered into the system so that questions from userscan be answered by the system in accordance with the rules that are owned by the system. The system is built for the plant from Thailand (Thai Herb) [11].

Besides the technical approach, socio-technical approach can also be done in building Ontology. This approach is used in constructing Ontology for herbs in Indonesia [12]. The methodology developed in building ontology is used to conduct a group discussion (FGD) and talk with experts in the field of medicinal plants. The data source of Ontology consists of five aspects: the aspect of pharmacology, health actors, taxonomy of plants, planting, and conservation of rare medicinal plants. Ontology built is still in the form of medicinal plants that have certain properties, not yet built in a collection of medicinal herbs to make Jamu that has been registered to the Badan Pengawas Obat dan Makanan (Indonesian Food and Drug Supervisory Agency).

Based on the literature review, research that will be conducted is developing Ontology about traditional Indonesian medicine. The result will be tested to establish rules that can be utilized by the users. The aim is to allow users to gain knowledge about Jamu. Overview of the rules is viewed from various sides, which are composition of the Jamu itself, the benefits of Jamu or plants used to make the Jamu, as well as the companies that produce Jamu.The difference from some of the existing literature is the chosen domain, especially for the study of medicinal plants Indonesia.The focus of previous research was on medical plants, not in the form of Jamu composed of medicinal plants. The other difference is the establishment of the rules, some of the literature still focuses on the use of SPARQL to obtain the data, not utilizing SWRL. The software used for the development of this system is the Protege 5.0.0-beta 2.1 with reasoner HermiT 1.3.8.413 for Ontology development and SWRL forfinding rules related toJamu. Hermit reasoner is used to gain inferences whileJava to manage SWRL results from the user's side.

\section{RESEARCH METHOD}

The main objective of the system built is to find broad information on herbal medicine in a simple way. Users do not have to perform queries that are too long. With SWRL, researcher will make rules regarding to herbs. Those rules are obtained from questions frequently asked by users. Results of the rules that have been made are expected to be widely used by the user to gain knowledge about herbs. Merging with another Ontology will enrich the knowledge acquired.

The following steps taken to build the Jamu ontology and SWRL are:

1. Planning; planning the domain that will be chosen in building ontology. In this research the selected domain was Jamu, Indonesian tradisional medicine.

2. Requirement Analysis;After selecting domain, analyzing information needed to gain knowledge from Jamu. In this step, data gathering from various recources from KnapSack database, Plantae Kingdom taxonomy from Integrated Taxonomy Information System (ITIS) and also from Indonesian Food and Drug Supervisory Agency (BPOM) is conducted.

3. Ontology Design. Based on the requirement analysis, conducting ontology design, starting from determining class, object property, and data property, as well as the relationship between classes. Classes are built not only for the sake of this moment, but class design is also expected to be developed better by adding new classes or adding new objects and data properties..

4. Testing Ontology. Testing is conducted by query of a design that has been built, whether it will generate expected information or not. If the testing result does not match, then process 2 until 4 is repeated again.

5. Building Rule. After the testing process is finish, the next step is to make rules that are often questioned by users by using SWRL.

6. Testing of SWRL results is also performed, if the inference engine result is wrong or if the process took too long in giving the rules result, then process 2 until 6 is repeated again.

7. Building a web page based on SWRL result. 


\section{RESULTS AND ANALYSIS}

\subsection{Ontology about Jamu}

The Jamu Ontology which is built is a development from Jamu Ontology that has been made previously [13]. The data used to construct Jamu Ontology is obtained by various sources [14][15][16]. Taxonomy used for Jamu is species from KingdomPlantae.Taxonomy are acquired in March 2016 from database Integrated Taxonomic Information System (ITIS) in http://www.itis.gov.

Hierarchy class of Jamu can be seen in Figure 1. Explanations of each class are:

1. Kingdom_Plantaehas subclasses like taxonomy in ITIS database. Each species or medical plants will be instance from Genus. For example, species Oryza Sativa Amylum (Rice) is instance of Genus_Oryza. Superclass for species Oryza Sativa Amylumis as follow: Kingdom_Plantae $\subset$ Subkingdom_viridiplantae $\subset$ Division_Tracheophyta $\subset$ Subdivision_Spermatophytina $\subset$ Class_Magnoliopsida $\subset$ Superorder_Lilianae $\subset$ Order_Poales $\subset$ Family_Poacea $\subset$ Genus_Oryza.

Kingdom_Plantae class can be developed for different kingdoms, such as Kingdom Animale, Kingdom Fungi, and others. The taxonomy built is very flexible and can be used for various purposes. In addition, the Ontology model meets the requirements in making Ontology classes, where the number of subclasses of each class should be more than one. If not, then the Ontology will be incomplete or there will be problems in developing it.

2. Jamu is a classcontaining information about Jamu whicheach instance must have information about composition of Jamu (composed Of Kingdom_Plantae), manufactured by the Company and illnesses are that cured by Jamu.

3. Type of Jamu has some subclasses like Jamu For Cough, Jamu For Pegel Linu and Jamu Saffron Colored Rice. It is a class to store information produced by SWRL.

4. Companyis a class to store information about companies that produce Jamu.

5. Efficacyis a class that contains information about efficacy of each part of medical plants. Each medical plants has part and each part has efficacy.

6. Part of Plants class contains information about part of certain plants, for example rhizome of ginger, seed of rice, etc.

7. Partcontains information about part of medical plants likeroot, rhizome, leaves, seed etc.

8. Illnesscontains information about diseases.

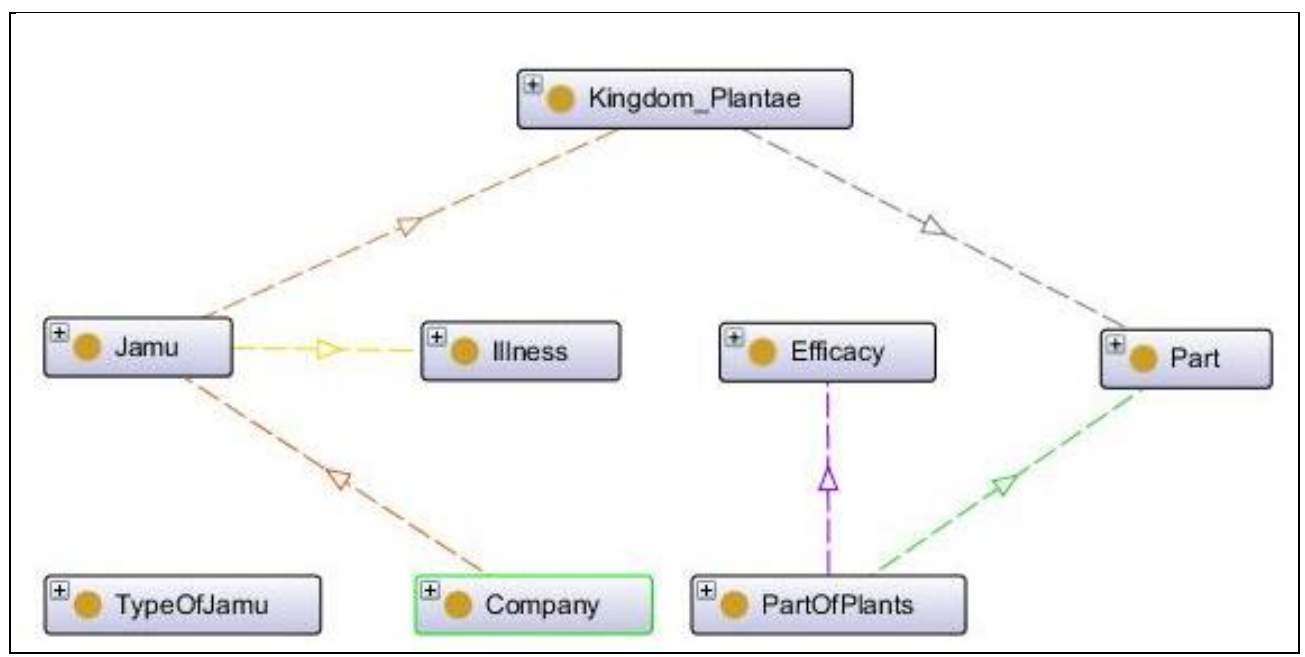

Figure 1. Hierarchy class of Jamu

Object property used in developing Ontology about Jamu can be seen in Table 1, while data property can be seen in Table 2 . As seen in Table 1, 8 object properties are used. Object property is used to relate domain type and range type. Domain and Range Type contain the class involved. As in Table 1, composed Of object property relates Plant class with Kingdom_Plantae.

Table 2 contains data properties used. There are two data properties, plantPopularName which is a data property from class Kingdom_Plantae, and plant Scientific Name which is a data property from Plants. 
Table 1. Object Property

\begin{tabular}{llll}
\hline Object Property & Domain Type & Range Type & Description \\
\hline composedOf & Plants & Kingdom_Plante & \\
efficacyOf & Efficacy & PartOfPlants & Inverse of : haveEfficacy \\
fromPlant & PartOfPlants & Part & \\
hasPart & Kingdom_Plantae & PartOfPlant & \\
haveEfficacy & PartOfPlants & Efficacy & Inverse of : efficacyOf \\
produce & Company & Jamu & Inverse of : produceBy \\
producedBy & Jamu & Company & Inverse of : produce \\
usedFor & Jamu & Illness & \\
\hline
\end{tabular}

Table 2. Data Property

\begin{tabular}{llll}
\hline Data Property & Domain Type & Data Type & Description \\
\hline plantPopularName & Kingdom_Plantae & String & Popular Name in different language (en,id,cn) \\
plantScientificName & Plants & String & Name in Science \\
\hline
\end{tabular}

Because each plant has different name in many languages, so we used data property "plant Popular Name" for each language. For example, Oryza Zativa Amylum and Oryza Zativa Frucuts have plant Popular Name "Padi" in Indonesian language (id) and "Rice" in English language (en). Jamu consists of several Kingdom_Plantae and only produced by the Company and can usedFor cure some diseases. Jamu not only consists of a few Kingdom_Plantae but must include the name of Company, because each Company will make Jamu with different medicinal plant composition, even if the Jamu has the same efficacy.
Ontology
about
Jamu
can
be
downloaded

at

https://www.dropbox.com/s/syq5qcy4uqrfke0/indonesiaHerbsv8.owl?dl=0

\subsection{Building Rule Using Semantic Web Rule Language (SWRL)}

Purpose of the rule is to facilitate users to obtain information. To understand how to build SWRL, an example will be provided. This example will obtain information about Jamuused for curing weak body or known as Jamu "Beras Kencur" (Saffrom Colored Rice). Rule to get that knowledge is:

jamu:Jamu(?jamu:x) ^jamu:usedFor(?jamu:x, ?jamu:Weak_Body) $\rightarrow$

jamu:JamuSaffronColoredRice(?jamu:x)

The antecedent (body) is definition ofJamuSaffronColoredRice.If it use natural language "is Jamu and used For Weak_Body and composed By Kingdom_Plantae". The consequent is Jamu Saffron Colored Rice. By using this rule, it does not need to create an instance of the class Jamu Saffron Colored Rice again. After enabling reasoner, the instance of the class Jamu Saffron Colored Rice can be seen on the instance (inferred). Results of SWRL can also bequeried by using DL. Query entered into the DL is the class that is defined in the rule built. Figure 2 shows the results of the query DL Jamu Saffron Colored Rice and Figure 3 is an example of explanation for JamuAir_Mancur_Beras_Kencur. By using Reasoner Hermit, inferred instances can be obtained and make it easier to find out why inferred instances happened.

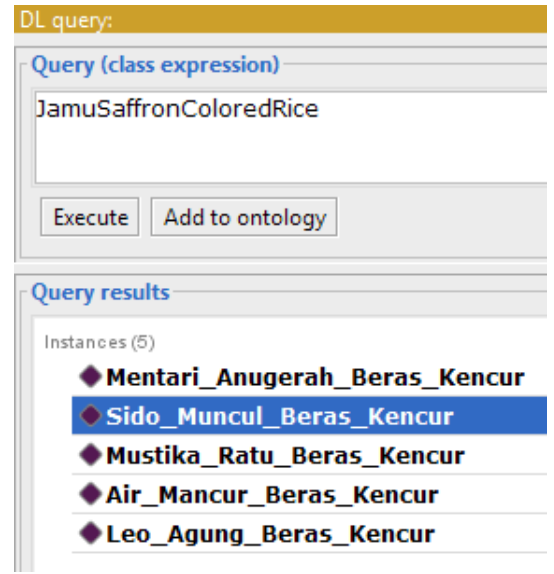

Figure 2. DL Query for Jamu Saffron Colored Rice 


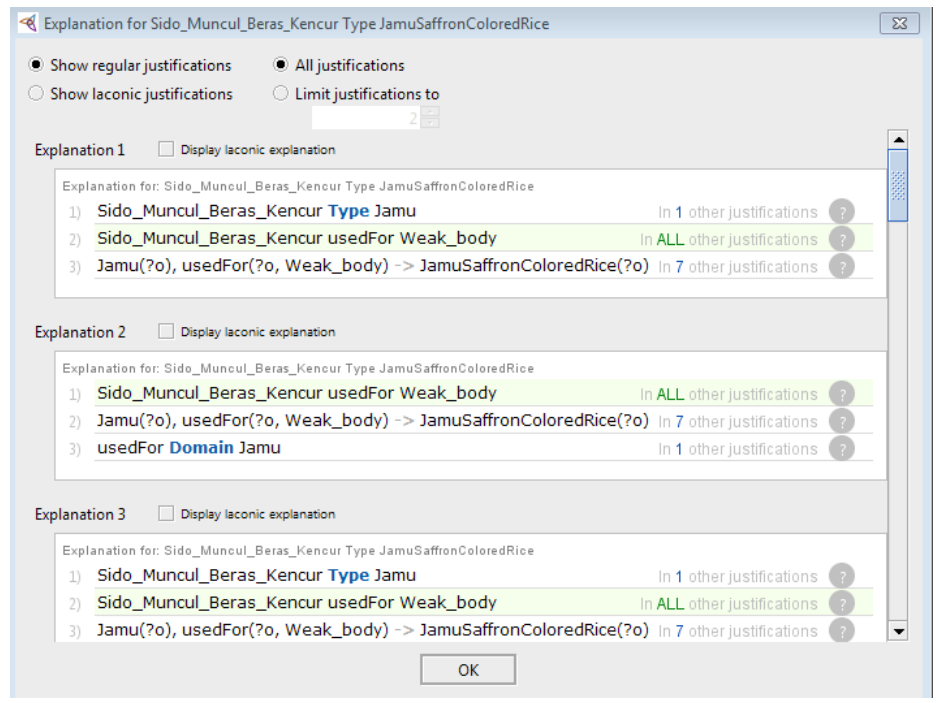

Figure 3. Explanation of Jamu Sido_Muncul_Beras_Kencur

Here are some examples of questions frequently asked by users to know about Jamu and answers resolved by using SWRL:

\section{What kind of Jamuis used to cure certain diseases and composition of Jamu}

Some diseases can be found in class Illness. Each instance of Jamu has object property used For. So we use this object property to found Jamu is used to cure certain diseases, so SWRL can use object property usedFor.

1.1. Rule for Jamu used to cure fatigue or we can call type of jamu is Pegel Linu is: jamu:Jamu(?jamu:o) ^jamu:usedFor(?jamu:o,jamu:Fatigue) $\rightarrow$ jamu:JamuForPegelLinu(?jamu:o)

1.2. Rule for Jamu "Galian Singset" that can used to reduce fat excess in the body, so that the body becomes lean, 'singset' and youthful look is:

jamu:Jamu(?jamu:o) ^jamu:usedFor(?jamu:o,jamu:Excess_fat_in_the_body) $\rightarrow$ jamu:JamuGalianSingset(?jamu:o)

1.3. Rule for Jamu which has Oryza_sativa_Amylum as one of its ingredient is : jamu:Company(?jamu:o) ^jamu:Jamu(?jamu:x)^jamu:producedBy(?jamu:x, ?jamu:o) $\wedge$ jamu:composedOf(?jamu:x,jamu:Oryza_sativa_Amylum) $\rightarrow$ jamu:JamuComposedOryza(?jamu:x)

\section{What are the name of Companies that produced Jamu}

2.1. Rule to find Company that produced Jamu Saffron Colored Rice is: jamu:JamuSaffronColoredRice(?jamu:x $)^{\wedge}$ jamu:Company(?jamu:y)^ ?jamu:producedBy(?jamu:x,?jamu:y) $\rightarrow$ ?jamu:CompanyForSaffronColoredRice(?jamu:y)

2.2. Rule for Company that produced Jamu with certain Plants using Oryza_sativa_Amylum is: jamu:Jamu(?jamu:x) ^jamu:Kingdom_Plantae(?jamu:y $)^{\wedge}$ jamu:Company(?jamu:z) ^jamu:composedOf(?jamu:x,jamu:Oryza_sativa_Amylum) ^jamu:producedBy(?jamu:x,?jamu:z) $\rightarrow$ jamu:CompanyUsedOryza(?jamu:z) 


\section{Kingdom_Plantae used to makeJamu}

3.1. Jamu composed Of some Kingdom_Plantaeso rule for plants for Jamu "Pegal Linu" as in 1.1 is jamu:JamuForPegelLinu(?jamu:o)^jamu:Kingdom_Plantae(?jamu:p) ^jamu:composedOf(?jamu:o,?jamu:p) $\rightarrow$ jamu:PlantsForPegelLinu(?jamu:p)

3.2. Jamu composed Of some Kingdom_Plantae and cure certain diseases, for example for curing weak body, so rule to find Kingdom_Plantae is: jamu:Jamu(?jamu:o) ^ jamu:Kingdom_Plantae(?jamu:p) ^ jamu:composedOf(?jamu:o, ?jamu:p) ${ }^{\wedge}$ jamu:usedFor(?jamu:o, jamu:Weak_body) $\rightarrow$ jamu:PlantsForWeakBody(?jamu:p)

When using Kingdom_Plantaeas a result of SWRL, then the inference engine will provide information regarding the superclass of each species in Kingdom_Plantae.

\section{About EfficacyOf Plants}

In contrast to the knowledge acquired in part 3, this section is focused on knowledge the efficacy of the medicinal plants (Kingdom_Plantae) and not on Jamu.

4.1. Rule for plants that has efficacy to cough medicine is jamu:Kingdom_Plantae(?jamu:p) ^ jamu:Part(?jamu:q) ${ }^{\wedge}$ jamu:PartOfPlants(?jamu:r) $\wedge$ jamu:Efficacy(?jamu:s) ${ }^{\wedge}$ jamu:hasPart(?jamu:p, ?jamu:r) ${ }^{\wedge}$ jamu:fromPlant(?jamu:r, ?jamu:q) $\wedge$ jamu:haveEfficacy(?jamu:r, ?jamu:s)^ jamu:haveEfficacy(?jamu:r, jamu:Cough_medicine) $\rightarrow$ jamu:PlantForEfficacyCoughMedicine(?jamu:p)

In the same way, we can obtain medicinal plants to treat another illness, such as for treating diarrhea, cold, high blood pressureand others.

4.2. What are benefits of certain medicinal Plants.

Rule for efficacy of Zingiber_officinale_Rhizoma is jamu:Kingdom_Plantae(?jamu:p) ^ jamu:Part(?jamu:q) ^ jamu:PartOfPlants(?jamu:r $)^{\wedge}$ jamu:Efficacy(?jamu:s $)^{\wedge}$ jamu:hasPart(jamu:Zingiber_officinale_Rhizoma,?jamu:r) ^ jamu:fromPlant(?jamu:r, ?jamu:q) ^ jamu:haveEfficacy(?jamu:r, ?jamu:s) $\rightarrow$ jamu:EfficacyPlantGinger(?jamu:s)

\section{Part of plants that can be used to cure diseases}

Each medicinal planthas a part that can be usedto treat certain diseases and each part has different efficacy. Rule to know which part ofa medicinal plantcan be used to treat "Cough" (example in 4.1) is : jamu:Kingdom_Plantae(?jamu:p)^ jamu:Part(?jamu:q) ${ }^{\wedge}$ jamu:PartOfPlants(?jamu:r) $\wedge$ jamu:Efficacy(?jamu:s)^ jamu:hasPart(?jamu:p,?jamu:r ${ }^{\wedge}$ jamu:fromPlant(?jamu:r,?jamu:q) ${ }^{\wedge}$ jamu:haveEfficacy(?jamu:r,?jamu:s) ^ jamu:haveEfficacy(?jamu:r, jamu:Cough_medicine) 
$\rightarrow$ sqwrl:select(?jamu:p, ?jamu:q, ?jamu:r)

\subsection{Building Rule using Sematic Web Rule Language (SWRL)}

The rules which have been built can be accessed through the Web page. Web pages are built using Java with JVM 8.0 and IDE Eclipse with Tomcat Web Server 8.0.The reason for using the Java language is Java has a library to query DL, while other languages do not have such capabilities. Example in the case of Jamu as described in the previous section, the result when given the input Jamu Saffron Colored Rice can be seen in Figure 4.

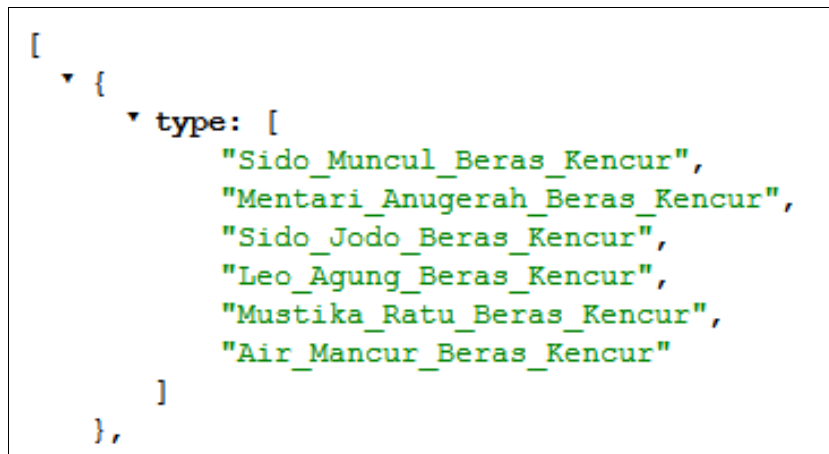

Figure 4. Result Query DL for Jamu Saffron Colored Rice

By entering library to process SWRL, the reasoner results can be obtained. The entire property of the class results can be obtained as well. The result depends on user's needs. By utilizing the results of inference using SWRL class, the query DL can be combined with SPARQL known as SPARQL-DL. Query to obtain the results as shown in Figure 4 is as follows:

Public static final String baseIRI= "http://www.owl-ontologies.com/Ontology1452764589.owl\#";

String path="JamuSaffronColoredRice"

String query $=$ "select distinct $*$ where \{

"Type(?type,<"+baseIRI+ path+">),

PropertyValue(?type, ?prop, ?value)"\}";

The web page can be developed further by utilizing the rules made in SWRL as described in Section 3.2. It can be developed to Question - Answer machine with domain of traditional Indonesian herbal medicine.

\section{CONCLUSION}

By utilizing Semantic Web technologies, Ontology for traditional Indonesian medicine calledJamu can be built. Combination ofOntology and SWRL enablesus to get the inference, which can be used to know the reason of the emergence of the rule. Advicethat can be given are to increase the number of individuals on Ontology, to complete ontology like add composition each Jamu and to complete the rule of Jamu Ontology. The results of the properties and values of the SPARQL-DL can be used as inputs which can be combined with other applications such as data mining.

\section{REFERENCES}

[1] D. K. RI, "Riset Kesehatan Dasar (RISKESDAS) 2013,” 2013.

[2] M. K. R. Indonesia, "Peraturan Menteri Kesehatan Republik Indonesia Nomor: 003/Menkes/Per/I/2010 Tentang Saintifikasi Jamu Dalam Penelitian Berbasis Pelayanan Kesehatan”, Jakarta Indonesia, 2010.

[3] F. M. Afendi, N. Ono, Y. Nakamura, K. Nakamura, L. K. Darusman, N. Kibinge, A. H. Morita, K. Tanaka, H. Horai, M. Altaf-Ul-Amin, and S. Kanaya, "Data Mining Methods for Omics and Knowledge of Crude Medicinal Plants toward Big Data Biology", Comput. Struct. Biotechnol. J., vol. 4, no. 5, p. e201301010, 2013.

[4] S. H. Wijaya, H. Husnawati, F. M. Afendi, I. Batubara, L. K. Darusman, M. Altaf-Ul-Amin, T. Sato, N. Ono, T. Sugiura, and S. Kanaya, "Supervised clustering based on DPClusO: Prediction of plant-disease relations using Jamu formulas of KNApSAcK database", Biomed Res. Int., vol. 2014, 2014.

[5] D. H. Yang, J. H. Kang, Y. B. Park, Y. J. Park, H. S. Oh, and S. B. Kim, "Association Rule Mining and Network Analysis in Oriental Medicine", PLoS One, vol. 8, no. 3, pp. 1-9, 2013. 
[6] M. O’Connor, H. Knublauch, S. Tu, B. Grosof, M. Dean, W. Grosso, and M. Musen, "Supporting rule system interoperability on the semantic Web with SWRL", Lect. Notes Comput. Sci. (including Subser. Lect. Notes Artif. Intell. Lect. Notes Bioinformatics), vol. 3729 LNCS, pp. 974-986, 2005.

[7] R. C. Chen, Y. H. Huang, C. T. Bau, and S. M. Chen, "A recommendation system based on domain ontology and SWRL for anti-diabetic drugs selection”, Expert Syst. Appl., vol. 39, no. 4, pp. 3995-4006, 2012.

[8] D. W. Wardani, S. H. Yustianti, U. Salamah, and O. P. Astirin, "An Ontology of Indonesian Ethnomedicine", in International Conference on Information, Communication Technology and System, 2014, pp. 47-52.

[9] V. Ganesan, S. Waheeta Hopper, and G. BharatRam, "Semantic Data Integration and Quering Using SWRL", in Trends in Network and Communications, vol. 197, D. Wyld, DavidC. and Wozniak, Michal and Chaki, Nabendu and Meghanathan, Natarajan and Nagamalai, Ed. Springer Berlin Heidelberg, 2011, pp. 567-574.

[10] R. Mohan. and G. Arumugam, "Developing Indian medicinal plant ontology using OWL and SWRL", in Second International Conference, ICDEM 2010, 2012, vol. 6411 LNCS, pp. 131-138.

[11] T. Kato, N. Maneerat, R. Varakulsiripunth, F. Engineering, and K. Mongkut, "Ontology-based E-health System with Thai Herb Recommendation 1 Sendai National College of Technology, Sendai, Japan”, vol. 1, 2009.

[12] M. Silalahi, D. E. Cahyani, D. I. Sensuse, and I. Budi, "Developing Indonesian Medicinal Plant Ontology Using Socio-Technical Approach", 2015, no. I4ct, pp. 39-43.

[13] R. Gunawan and K. Mustofa, "Pencarian Aturan Asosiasi Semantic Web Untuk Obat Tradisional Indonesia", Jurnal Nasional Teknik Elektro dan Teknologi Informasi(JNTETI), vol. 5, no. 3, pp. 192-200, 2016.

[14] Y. Nakamura, H. Asahi, M. Altaf-Ul-Amin, K. Kurokawa, and S. Kanaya., "KNApSAcK: A Comprehensive Species-Metabolite Relationship Database". [Online]. Available: http://kanaya.naist.jp/jamu/top.jsp. [Accessed: 30Mar-2015].

[15] Badan Pengawas Obat dan Makanan Indonesia, "Produk Obat Tradisional". [Online]. Available: http://ceknie.pom.go.id/. [Accessed: 24-Jan-2016].

[16] Badan Pengawas Obat dan Makanan Indonesia, "Obat Bahan Alami Indonesia". [Online]. Available: http://www.pom.go.id/index.php/oai/. [Accessed: 24-Jan-2016].

\section{BIOGRAPHIES OF AUTHORS}

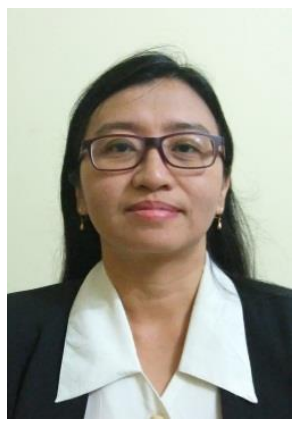

Ridowati Gunawan received Bachelor of Informatics Engineering form Duta Wacana Christian University, Yogyakarta, Indonesia in 1996, received Master of Engineering from Universitas Gadjah Mada, Yogyakarta, Indonesia in 2002. Currently she is a lecturer at Department of Informatics in Universitas Sanata Dharma Yogyakarta, Indonesia and pursuing his doctoral program in Computer Science at Department of Computer Sciences \& Electronics in Universitas Gadjah Mada, Yogyakarta, Indonesia. Her research areas of interest are data mining, database management system, knowledge management, and information systems.

Email : ridowati.gunawan@mail.ugm.ac.id; rido@usd.ac.id; ridowatig@gmail.com

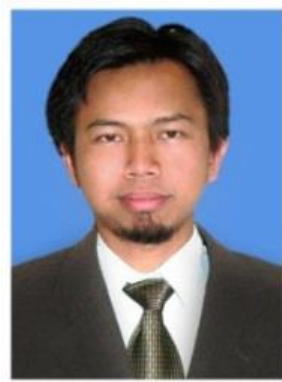

Dr. Techn. Khabib Mustofa, S.Si., M.Kom. received Bachelor of Computer Science from Universitas Gadjah Mada, Yogyakarta, Indonesia in 1997, received Master of Computer Science from Universitas Gadjah Mada, Yogyakarta, Indonesia in 2001, and receieved Ph.D. from Vienna University of Technology, Austria in 2007. Currently he is a lecturer at Department of Computer Science \& Electronics in Universitas Gadjah Mada, Yogyakarta, Indonesia. His research areas of interest are semantic web, web services, mobile application and information management.

Email: khabib@ugm.ac.id 